\title{
Photosensitive Dermatitis
}

National Cancer Institute

\section{Source}

National Cancer Institute. Photosensitive Dermatitis. NCI Thesaurus. Code C4816.

Dermatitis caused or precipitated by exposure to ultraviolet sunlight, or by mediating phototoxic or photoallergic material in response to ultraviolet sunlight. 